\title{
The Impact of Adding Written Discourse to Six Year Olds' Mathematics Explanations within a Problem-Based Learning Unit
}

\author{
Nicole V. Gearing ${ }^{1 *}$, Lynn C. Hart ${ }^{2}$ \\ ${ }^{1}$ Utah Valley University, Orem, Utah, USA \\ ${ }^{2}$ Georgia State University, Atlanta, Georgia, USA \\ *Corresponding Author: nicole.gearing@uvu.edu \\ Citation: Gearing, N. V. and Hart, L. C. (2019). The Impact of Adding Written Discourse to Six Year Olds' \\ Mathematics Explanations within a Problem-Based Learning Unit. European Journal of STEM Education, 4(1), \\ 03. https://doi.org/10.20897/ejsteme/3952
}

Published: April 29, 2019

\begin{abstract}
Communicating their thinking in mathematics is challenging for young children. This research studied the change in six-year old students' oral and written solution explanations before and after six problem-based mathematics lessons that focused on developing conceptual understanding of adding or subtracting a 2digit number and a multiple of ten. Participants were assigned to a comparison group or an intervention group based on the classroom in which they were assigned. All students completed a pre-and postassessment. Both groups received the same, six problem-based lessons. To encourage growth in their communication skills, students in both groups were asked to talk about their strategies, while the intervention group was asked to both talk and write about their strategies during each lesson. Oral and written pre-and post-assessments were scored using a rubric adapted from the Project M3 curriculum (Gavin et al., 2006-2008) and interrater reliability was established. T-test analyses were conducted to determine if a significant difference exists between first-graders oral and written mathematical explanations within discourse modes (comparing pre/post writing or pre/post talking) and between discourse modes (comparing talking and writing) for the intervention and comparison groups. A significant difference between discourse modes was found on the pre-assessments but not the post-assessments, suggesting that increasing oral discourse decreased the gap between the children in both groups ability to talk and write about their thinking. A significant difference was found within discourse modes for the intervention group, but not the comparison group, suggesting that adding written discourse to problem-based lessons further increased the children in the intervention group's ability not only to write about their solutions, but also to talk about their thinking. In order to give a glimpse of the development of the first graders in the intervention group's oral and written mathematical explanations, the work of three focus students was selected to share. Through the use of problem-based instruction and cognitively demanding tasks along with the development of sociomathematical norms and discourse knowledge, the young children in this study were able to improve their verbal and written communications skills.
\end{abstract}

Keywords: sociomathematical norms, social constructivism, oral discourse, written discourse, problembased lessons

\section{INTRODUCTION}

Reform movements around the mathematics education of students in primary grades 1-5 (approximate ages 5 to 10 years) often focus on developing children's ability to communicate their mathematical reasoning when 
problem solving. While this study focused on the United States Common Core State Standards for Mathematics (2014), this shift is evidenced in numerous country's curriculum reform documents including, Sweden (2011), Finland (2014), England (2014), the Netherlands (2016), and others (Pont, 2018). Each of these revisions suggest developing children's ability to communicate mathematical reasoning when solving problems. While we acknowledge that communication is an essential part of learning in mathematics, it is often difficult for young children to talk (Moyer, 2000) because they may not have had rich experiences in sharing their mathematical reasoning with others. While talk and writing are not the only forms of mathematical communication, there are several benefits of incorporating these skills during mathematics lessons. Talking makes student's ideas public and it gives students the opportunity to explain and justify their thinking, further deepening their conceptual understanding of mathematical concepts (NCTM, 2000). Writing about mathematical ideas creates a written record of a child's thought process (Lee, 2006) and provides every child with the opportunity to engage in explaining their thinking, rather than only the few called upon during a class discussion. Finally, talking and writing about mathematical thinking gives teachers a better understanding of what a child knows or the misconceptions a child may have about a concept.

When building communication skills in the mathematics classroom of very young students, writing is often not part of the conversation. However, in the U.S. the practice standards put forth by NCTM expect children to explain the reasoning used to solve problems. The CCSSM (2010) third Standard for Mathematical Practice (SMP) expects children, beginning in Kindergarten (age 5), to be able to construct viable arguments and critique the reasoning of others. In the explanation of the standard it says, 'students at all grades can listen or read the arguments of others, decide whether they make sense, and ask useful questions to clarify or improve the arguments' (Common Core State Standards Mathematics [CCSSM] 2010, p. 2). While the standard does not explicitly require children to write about their reasoning, it can be inferred that this is an expectation by asking students to read the arguments of others. This is similar to the Department for Education National Curriculum in England for Key Stages 1 (5-7 years) and 2 (7-11 years) that states that students should be able to "reason mathematically by following a line of enquiry, conjecturing relationships and generalizations, and developing an argument, justification or proof using mathematical language" (Department for Education, 2013, p. 3). Additionally, since the focus of mathematics for young children has often been computation, students frequently learn to compute without making sense of the procedures they use, leading to an inability to apply procedures to solve real world problems (National Research Council, 2000). Being able to reason mathematically and communicate mathematical thinking both orally and in writing about procedural and conceptual knowledge clearly have become vital skills for children to acquire as they move into the $21^{\text {st }}$ century workforce (Boaler, 2016).

With changes in standards come changes in assessment. If standards are addressing the need to communicate mathematical thinking, this skill must be assessed. One way for teachers to assess understanding in their classrooms is through the use of oral discourse; however, this can be particularly difficult when teachers have twenty plus children in their class. Achievement tests frequently rely on multiple-choice items, making it challenging to assess a child's ability to construct a viable argument or critique the reasoning of others. As is evident, explaining one's thinking cannot reasonably be evaluated through use of many traditional assessments. As a result, constructed response items requiring written explanations are being added to some assessments such as the Partnership for Assessment of Readiness for College and Careers (PAARC) (2016) in the U.S., creating a need to develop students' ability to also explain their mathematical reasoning through writing.

\section{THEORETICAL PERSPECTIVES}

\section{Social Constructivism}

Smith and Stein (2015) make the following comment about U.S. schools:

The instructional practices used in the majority of our nation's classrooms will not prepare students for new demands. National studies have shown that American students are not routinely asked to engage in conceptual thinking or complex problem solving (Stigler and Hiebert, 1999) ... It is unrealistic to expect students to learn to grapple with the unstructured, messy challenges of today' world if they are forced to sit silently in rows, complete basic skills worksheets, and engage in teacher-led discussions ...” (p. 1)

Fortunately, methods for teaching and learning mathematics are changing, with a primary influence being the commonly accepted theoretical perspective of social constructivism, which suggests that learners must construct their own knowledge (Ernest, 2008). And, as suggested above, mathematical understanding and reasoning is not only constructed within an individual, it is also socially constructed, through conversations and discourse, a key component needed for intellectual growth (Tharp and Gallimore, 1991). 


\section{Mathematical Discourse}

The importance of developing spoken language in mathematics is recognized internationally. In England the Department for Education (2013) states in their Key Stage 1 curriculum, "The quality and variety of language that pupils hear and speak are key factors in developing their mathematical vocabulary and presenting a mathematical justification, argument or proof." In the U.S. the NCTM (2015) points out that spoken language "gives students opportunities to share ideas and clarify understandings and construct convincing arguments regarding why and how things work ..." (p. 29). Key features of mathematical discourse include special key words, unique visual mediators, distinctive routines, and generally endorsed narratives (Sfard, 2012). However, with young children, mathematical discourse is often limited to oral exchanges. There are some research-based benefits to including written discourse in instruction.

The most immediate benefit is the need to help children communicate their mathematical thinking through writing for the purpose of assessment. However, the benefits of writing in the mathematics classroom go beyond preparing for the test. The act of writing encourages children to reflect on the mathematics they have learned and actively engage in thinking about mathematical experiences (Burns, 2004). For example, Pugalee (2004) found that the process of writing helped high school students consolidate their thinking and develop metacognitive awareness. Bicer et al. (2013) found that for middle school students writing acted a mediator in the problem-solving process. The National Council for Teachers of Mathematics (2000) recognizes that writing helps students consolidate their thinking. Further, writings children create serve as a record of mathematical thought (Lee, 2006) that can demonstrate student growth and understanding. Unfortunately, limited research has been done involving oral or written discourse in very young children.

The use of oral and written discourse also promotes equity in the mathematics classroom. Engaging in mathematics through speaking creates a space where students begin to take ownership of what they are learning by sharing with their peers. When students share their solution strategies and reasoning, the gap between students who understand the concept and those who do not understand the concept is reduced (Boaler, 2016). Additionally, giving students the opportunity to participate in discourse provides the teacher insight as to which students have a solid understanding of a mathematical concept and which students have misconceptions (Yackel and Cobb, 1996). Understanding a student's thought process helps the teacher evaluate what the child knows or does not know, in turn helping the teacher improve access and equity within the classroom (Yackel, 1995). Giving children the opportunity to write about their solution strategy affords the teacher the opportunity to understand the thinking of more students than the few who are able to orally share their solution strategies during a typical lesson.

\section{An Expanded View of Discourse}

Communication, within the context of mathematics classrooms should not be limited to oral exchanges. This is supported in the U.S. by the NCTM (2015). They state, 'mathematical discourse includes the purposeful exchange of ideas through classroom discussion, as well as through other forms of verbal, visual and written communication' (p. 29). In the U.K. at Key Stages 1 and 2 they introduce the notion of students reading and spelling mathematical vocabulary, "at a level consistent with their increasing word reading and spelling knowledge." Utilizing visual, written communication in young children's classrooms creates a record of children's mathematical thinking (Lee, 2006) that can be used to evaluate growth over time and provides another avenue for communication and is a valuable form of discourse in the classroom.

Casa and colleagues (2016) define writing mathematically as writings that "engage students in reasoning" (p. 3). They identify four types of mathematical writing including exploratory, informative/explanatory, argumentative, and mathematically creative. Because this study sought to help children develop their ability to explain their thinking, informative or explanatory writing was used. However, it is clear there are several ways to incorporate writing within the mathematics classroom.

Understanding how to write within a certain genre is referred to as discourse knowledge in literacy (Olinghouse and Graham, 2009). When young children begin to learn to write in a new genre or discipline such as mathematics, they must learn the expectations of that discipline. Several intervention studies have demonstrated that actually teaching discourse knowledge, what the expectations are for that discipline, can enhance writing performance (e.g., Fitzgerald and Danielham, 1987). Using specific mathematical vocabulary (using add instead of put together), distinguishing between strategies (counting by ones vs. counting by tens), or knowing how to demonstrate a proof (using concrete materials or drawing models) are all discipline specific or discourse knowledge needed for communication in mathematics. Since many young children are not exposed to writing about their mathematical reasoning, this discourse knowledge must be taught and developed. Casa (2015) suggests connecting children's oral discourse to written discourse to build a foundation for this discourse knowledge. However, many children lack the ability to use oral language to talk about their thinking in meaningful ways. This is supported by the work of Mercer and colleagues (1999). In this study, Mercer and colleagues worked with teachers in a specialized program to help their 9-10 year old students develop awareness of language as they talk with peers through collaboration. 
He found a noticeable shift in the children's language, confirming the importance of explicitly teaching children how to effectively use language. More recently, Mannion and Mercer (2016) worked with older children (grades 79) in a Learning to Learn (L2L) project that embedded 'exploratory talk' and 'reflective journals' as two components in a project aimed at developing children as learners across disciplines. Although L2L had several other components and enhanced subject attainment cannot be attributed solely to these two components, the model as a whole helped older students to speak, listen, and reason more effectively. More specifically to mathematics instruction, Williams and Casa (2015) encouraged first graders to discuss the symmetry of a leaf, putting their ideas in what they refer to as a "talk frame." The children were then asked to go back to their seats and write about whether or not a leaf was symmetrical. The researchers expected the students to copy the ideas discussed as a whole group, however, most children connected the ideas they heard while participating in a class discussion with their own thinking, demonstrating that, with support, very young children are able to explain their thinking in writing.

\section{THE STUDY}

Given the importance of oral and written discourse for young children, a project was conducted in four grade 1 classrooms (6 year olds) in a Title 1 school (a school with a high number of children from low socioeconomic families) in a large metropolitan school district in the southern U.S. to look at the benefits of adding written discourse to oral discourse within lessons that took a conceptually based instructional approach. The purpose of the study was to explore first-grade children's ability to talk and write about their mathematical thinking within the context of problem-based lessons. All four first-grade classrooms at the school participated in a set of six problembased lessons taught by the first author. Problem-based lessons require students to engage in higher cognitive demand tasks, allow for varied solution strategies, which often elicits more mathematical discourse (Stein et al., 2008). Each of the four classrooms were randomly assigned to a comparison group or an intervention group. Both groups of students (comparison and intervention) participated in problem-based lessons rich in oral discourse that focused on adding and subtracting two-digit numbers and multiples of ten. The intervention group also wrote about how they solved problems during each lesson. Pre/post written and oral mathematical explanations were collected at the beginning and completion of a six-lesson problem-based unit in the numbers and operations domain.

\section{Participants and Context}

While all students in the classrooms participated in the problem-based lessons, pre and post assessments were only analyzed for students with parental consent $(n=50)$. See Table 1 for detailed participant demographics. The teachers of the students included four female teachers, three African-American and one Caucasian. The two comparison teachers were African American. One Intervention teacher was African American while the other was Caucasian.

Table 1. Participant Demographics

\begin{tabular}{lcc}
\hline & Comparison Group & Intervention Group \\
\hline Number of Participants & 23 & 27 \\
\hline Male & 7 & 13 \\
\hline Female & 16 & 14 \\
\hline IEP & 4 & 2 \\
\hline Struggling Math Learners & 3 & 5 \\
\hline English Language Learners & 2 & 7 \\
\hline Gifted & 2 & 2 \\
\hline
\end{tabular}

The school's mathematics curriculum was Eureka Math. Eureka Math is a widely utilized K-12 mathematics curriculum used in the U.S. It aligns with the Common Core State Standards and is free for use in schools (Great Minds, 2016). Each Eureka lesson contains the same lesson structure: fluency practice, application problem, concept development, and 10 minutes for student debrief. During the time of this study the first-grade teachers were asked to proceed through the Eureka Math Module lessons four days a week. Students participated in the problem-based lessons with the researcher the remaining day. The present study focused on base-ten addition and subtraction, the mathematics unit occurring on the other four days was a unit on Geometry. While the students were focusing on Geometry during the study, they had previously focused on base-ten addition and subtraction in the fourth Eureka unit. Topics in that unit, module 4, had included tens and ones, comparison of two-digit numbers, addition and subtraction of tens, addition of tens or ones to a two-digit number, varied problems within 20 , addition of tens and ones to a two-digit number. Within that module, students were presented with the strategy of direct modeling counting on, single-digit sums, and add ones and ones or tens and tens. 


\section{METHODS}

\section{Data Collection}

Prior to beginning data collection, the researcher observed a mathematics lesson in each classroom to develop a picture of a typical lesson and what, if any, sociomathematical norms had been developed. The researcher also conducted a 30-minute interview with each of the teachers, asking about how her students typically talk and write in mathematics class. Subsequently students in all four classes completed an oral and written pre-assessment. The written assessment consisted of presenting each class with an Add To: Result Unknown problem (CCSSM, 2010). Students were asked to solve the problem and then write a note to the teacher telling her how they solved the problem. The oral pre-assessment was done individually. Students were asked to solve a different Add To: Result Unknown problem. They were then asked to tell the researcher orally how they got the answer by answering the question, "Can you tell me how you got your answer?". The problems for the pre and post assessments can be found in Table 2. Each response was recorded and transcribed. The pre-assessment was followed by each class participating in a 6-lesson problem-based unit. At the completion of the unit, students participated in the same written and oral assessments with new problems.

Table 2. Assessment Problems

\begin{tabular}{ll}
\hline Assessment & Problem \\
\hline Pre-Oral & Skylar had 32 balloons for her birthday. She blew up 30 more balloons. How many balloons does Skylar have now? \\
\hline Pre-Written & Mrs. Smith had 28 pencils for the class. She found 30 more pencils. How many pencils does Mrs. Smith have now? \\
\hline Post-Oral & Joe had 26 rocks in his collection. He went on a walk and found 40 more. How many rocks does Joe have now? \\
\hline Post-Written & Eric had 36 cookies for a class party. He baked 40 more cookies. How many cookies does Eric have now? \\
\hline
\end{tabular}

\section{The Intervention}

Although students in this study previously had lessons on how to add two-digit numbers, pre-assessment results indicated that most students were not able to explain how they solved problems with detail, often saying "I just knew" or "I added". Therefore, an important emphasis in all the classrooms during the 6-lesson unit, was to cultivate highly developed sociomathematical norms, which refers specifically to the norms developed in the mathematics classroom. This was important since often children have a difficult time explaining their thinking because they are unsure what it means to explain (Levenson, 2013). Intentionally focusing on language norms was supported by Mercer et al. (1999) who found that explicitly teaching children how to use language to reason and when working collaboratively with peers showed an improvement in their oral communication.

Sociomathematical norms are "distinct from general classroom social norms in that they are specific to the mathematical aspects of students' activity" (Yackel and Cobb, 1996, p. 458). During all the lessons, an effort was made to help the students develop a shared understanding of what a meaningful explanation constitutes (Yackel and Cobb, 1996). When shared understandings are established, learning occurs as children share how they solved problems and their peers make sense of their mathematical reasoning. Children also make judgments about the similarities and differences in the solution strategies shared and feel comfortable questioning and challenging the thinking of their peers (Yackel, 1995).

While sociomathematical norms usually refer to oral discourse within a mathematics classroom, these norms can also be established when children are sharing their explanations through written discourse. Therefore, the same conversations used to develop sociomathematical norms for talking about mathematical thinking were used to develop children's written responses. In the classrooms of this study, developing norms included what it meant to explain how you solved a problem to peers and the class. As mentioned, student explanations at the beginning of the unit often were limited to "I just knew" or "I just added the two numbers together." However, in a classroom where clear sociomathematical norms are developed, what counts as a sufficient explanation is clear to the group, and peers understand exactly what the student did to solve the problem.

To develop and encourage more specific explanations the researcher asked questions such as, "What did you do to add the two numbers together?" or "How did you add the two numbers together?" Through these conversations, the students began to include these ideas in their own explanations both with their peers and when they were selected to share with the class. For example, in the third lesson in the unit the students investigated the number of Pringles used to make a Pringle Ringle (stacking Pringle chips in a circular fashion) (Fletcher, 2016). The problem they solved was, There are 78 Pringles in a stack. Some were used to make a Pringle Ringle. Now there are 20 left in the stack. How many Pringles are in the Pringle Ringle? In one class the researcher asked Daniel to explain his strategy. He responded, "I drew 78 and then I crossed out 20 and then I counted the rest and I got 58." Before assuming a particular method for drawing 78, the researcher asked, "How did you draw your 78 Pringles?" He responded, "I drew 78 ones." The researcher proceeded to draw 78 Pringles on the board. As she drew the 78 Pringles some of the students were commenting, "Can't you just make tens?" and "I can do that faster with some 
tens and ones." The researcher asked the students to hold on to their thoughts, reminding them that Daniel was sharing his strategy and he did not use tens and ones. While the researcher was encouraged that students saw a more efficient way of solving the problem, she reminded the students that Daniel was telling us exactly what he did to solve the problem. By reinforcing and honoring an explanation that mirrored exactly the strategy the student had used, other students began to understand what it meant to explain how they solved the problem and how to differentiate strategies. Once the researcher finished drawing and crossing out 20, she asked Daniel, "How did you know the answer was 58?" Daniel replied with a huge grin, "I counted by ones." Clearly proud that his strategy had been honored, Daniel was able to explain that he drew all of the Pringles, crossed 20 out and counted the remaining. While more efficient strategies emerged in later discussions, focusing on unpacking exactly what the student had done was critical in developing the sociomathematical norms of the class and in modeling what it meant to show or explain your strategy. After conversations such as this, students began including how they counted in their oral and written explanations.

Interestingly, Daniel repeated his same, direct model, count by ones strategy the following week. In this lesson, the children were adding $40+47$. When the researcher asked him why he drew out $40+40$ by ones, he responded, "I didn't know how to draw what I did. I had my answer by the time I got to my seat." The researcher asked him to explain how he knew the answer. He said, "I knew that $40+40=80$ and 7 more equals 87 , but I didn't know what to write on my paper." Daniel mentally used a more sophisticated solution strategy than counting all, however, he was unsure how to write his thinking on paper, likely because he was the first student to mention the use of an invented algorithm and had no previous experience to relate to. Therefore, the researcher/teacher selected him to share so that she might help Daniel and the other students in a similar predicament decide how to translate their mental math solutions to paper.

\section{Data Analysis}

Pre and post student assessments were scored by two independent scorers who were trained using the rubric in Appendix A. The rubric was adapted from Gavin et al. (2006-2008), Rubric for Student Mathematician's Journal, by the first and second authors. A student could receive a score of $0-3$ on each assessment. Group mean scores were calculated for each of the 8 assessments, i.e. pre and post written and oral results for both the intervention and the comparison group. Quantitative results are shared next, followed by qualitative analysis of three focus children's assessments.

\section{RESULTS}

\section{Quantitative Rubric Results}

In order to determine if there was a significant difference between all the children's oral and written mathematical explanations before and after the problem-based lessons, paired-sample t-tests were conducted to determine differences in the children's oral and written mathematical explanations before and after the problembased lessons. Because more than one t-test was conducted using the same set of data, the Bonferroni Method was used to determine the alpha level to avoid a type I error, falsely finding significant results (Armstrong, 2014). Since eight t-tests were conducted (see Table 3 and 4), an alpha level of .006 was used to determine significance for each t-test. Effect size was also calculated and reported for each t-test using G*Power 3.1 (Faul et al., 2009). Effect size is reported to communicate the size of the effect of results (Wright, 2003). Cohen (1988) interprets an effect size around .2 as small, .5 as moderate, and .8 as large. The greater the effect size, the more practical significance of the results.

\section{Comparing Within-Group Means between Discourse Modes}

A paired-sample t-test was conducted to compare the mean oral and mean written scores of the comparison group and of the intervention group prior to the problem-based lessons (See Table 3). These results suggest that prior to the problem-based lessons, there was a significant difference within both group's ability to explain their mathematical thinking using oral language versus their ability to explain their thinking using written language.

Paired-sample t-tests were again conducted to compare the within-group mean oral and written scores of the students in the comparison and the students in the intervention groups at the completion of the problem-based lessons (See Table 3). The post results showed no significant difference in the mean scores of students from both groups on the oral and written explanations assessment. However, there was less difference between the intervention group's oral and written scores than the comparison groups oral and written scores. More simply, the gap between the written and oral results was reduced more in the intervention group. 
Table 3. Results of t-test and Descriptive Statistics for Comparing between Discourse Modes (Pre/Post)

\begin{tabular}{|c|c|c|c|c|c|c|c|c|c|}
\hline \multirow[b]{3}{*}{ Group } & \multicolumn{6}{|c|}{ Language Mode } & \multicolumn{3}{|c|}{ Difference } \\
\hline & \multicolumn{3}{|c|}{ Oral } & \multicolumn{3}{|c|}{ Written } & \multirow[b]{2}{*}{$d f$} & \multirow[b]{2}{*}{$t$} & \multirow[b]{2}{*}{ Cohen's $d$} \\
\hline & $M$ & $S D$ & $n$ & $M$ & $S D$ & $n$ & & & \\
\hline Pre-Comparison & 5.43 & 2.50 & 23 & 3.48 & 2.25 & 23 & 22 & 4.8914* & .60 \\
\hline Pre-Intervention & 4.85 & 2.33 & 27 & 3.37 & 2.31 & 27 & 27 & $3.9507 *$ & .46 \\
\hline Post Comparison & 5.62 & 2.50 & 21 & 4.67 & 2.61 & 21 & 20 & 2.3271 & .27 \\
\hline Post Intervention & 6.36 & 1.87 & 25 & 6.04 & 2.14 & 26 & 24 & 0.8382 & .11 \\
\hline
\end{tabular}

Table 4. Results of t-test and Descriptive Statistics for Oral and Written Explanation Scores

\begin{tabular}{|c|c|c|c|c|c|c|c|c|c|}
\hline \multirow[b]{3}{*}{ Group } & \multicolumn{6}{|c|}{ Time } & \multicolumn{3}{|c|}{ Difference } \\
\hline & \multicolumn{3}{|c|}{ Pre } & \multicolumn{3}{|c|}{ Post } & & & \\
\hline & $\bar{M}$ & $S D$ & $n$ & $\bar{M}$ & $S D$ & $n$ & $d f$ & $t$ & Cohen's $d$ \\
\hline Oral Comparison & 5.43 & 2.50 & 23 & 5.62 & 2.50 & 23 & $\overline{20}$ & 0.8667 & .06 \\
\hline Oral Intervention & 4.85 & 2.33 & 27 & 6.36 & 1.87 & 25 & 24 & $4.1167^{*}$ & .50 \\
\hline Written Comparison & 3.48 & 2.52 & 23 & 4.67 & 2.61 & 21 & 20 & 1.8199 & .34 \\
\hline Written Intervention & 3.37 & 2.31 & 27 & 6.04 & 2.14 & 26 & 25 & $5.2021^{*}$ & .87 \\
\hline
\end{tabular}

\section{Comparing within group means within Discourse Modes}

Paired-sample t-tests were conducted to compare the mean oral explanation scores each group received before and after the problem-based lessons (See Table 4). These results suggest that adding writing to problem-based lessons may increase students' ability to explain their mathematical thinking orally.

Paired-sample t-tests were also conducted to compare the mean written explanation scores each group received before and after the problem-based lessons (See Table 4). Not surprisingly, these results suggest that adding writing to an instructional problem-based unit may increase student's ability to communicate their thinking in writing in a short 6-week period of time. Further, we found that simply engaging in problem-based lessons where oral discourse is used as a medium to explain mathematical thinking was not enough to produce more detailed written explanations among the children in the comparison group.

The results from these analyses indicated that when adding writing to problem-based instruction, children are better able to both talk and write about their mathematical thinking. However, these quantitative results provide a limited picture of the nature of the change seen in the children's ability to engage in written and oral discourse. Therefore, qualitative analyses of a purposefully selected focus children are shared and discussed here.

\section{Qualitative Focus Children Examples}

Focus Child Pre-Assessment Results. In order to give a glimpse of the development of the first graders in the intervention group's oral and written mathematical explanations, the work of three focus students were selected to share. The students were selected to demonstrate a range of ability before the unit and growth at the completion of the unit.

\section{Focus Student 1: Maria}

Maria, an English as a Second Language Learner, was chosen as her responses on the pre-assessment were typical of her peers, that is, they were vague, did not demonstrate conceptual understanding, and lacked the use of formal and/or informal mathematical vocabulary. Like many of her peers in this context, Maria struggled with the mathematics content as well as with her ability to communicate her thinking orally or in writing prior to the problem-based unit.

Maria's pre-assessment oral explanation transcription is seen in Figure 1. As is evident, her account lacks detail. While it suggests that she thinks that the two numbers should be added together by her use of the word 'plus', there is no description of how she reached her incorrect solution. She only shares that she just knew the answer because she was 'thinking in her head.' From both her representation and explanation, a teacher could not determine how Maria came to 42 as her solution.

Maria's pre-assessment written explanation is seen in Figure 2. Like many of her peers, she shared less about her solution strategy when asked to write about it; but, similar to her oral explanation, her written explanation reveals her difficulty with the mathematical concept of adding tens and ones as well as her inability to communicate what she did to solve the problem. From her explanation, we are unable to determine how Maria came to a solution of 38. Note that Maria was asked to translate her invented spelling when necessary. 
Skylar had 32 balloons for her birthday. She blew up 30 more balloons. How many balloons does Skylar have now?

Use numbers or pictures to find the solution to the story

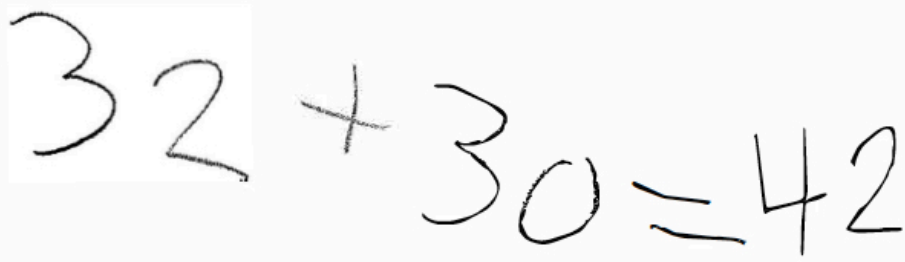

Solution:

I was thinking in my head and I just knew it.

Because 32 plus 30 equals 42 .

Figure 1. Maria’s Oral Pre-Assessment

Mrs. Smith had 28 pencils for the class. She found 30 more pencils.

How many pencils does Mrs. Smith have now?

Use numbers or pictures to find the solution to the story
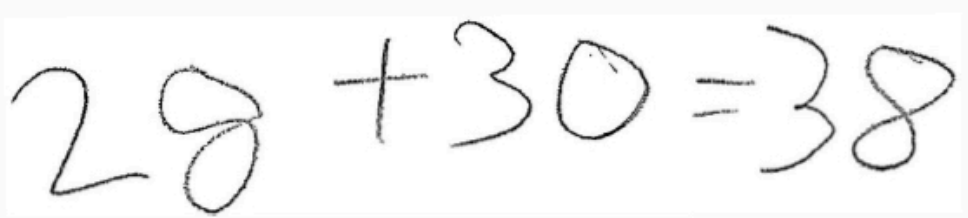

Solution:

Use words to explain how you found your solution:

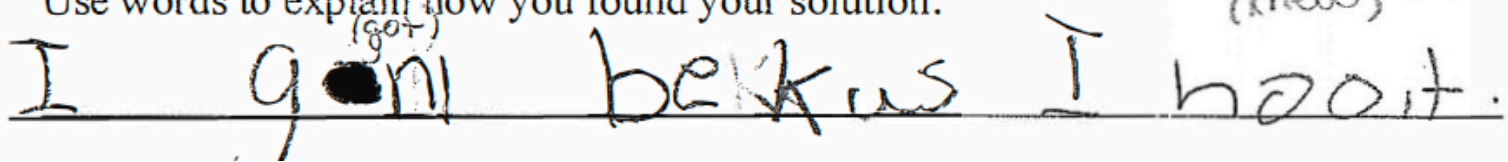

Figure 2. Maria's Written Pre-Assessment

\section{Focus Student 2: Paris}

Paris is a gifted student. Her teacher explained that she is an excellent math student but like many of her peers, often has a difficult time explaining how she solved problems. This could be because she solves problems so 
quickly that she is not metacognitively aware of their solution strategies, or because she is not sure what is expected of her when she is asked the question, "Can you tell me how you got your answer?"

On the oral pre-assessment (Figure 3), Paris interpreted the problem as subtraction rather than addition, however her math is consistent with her interpretation. When asked about why she subtracted, she explained the balloons blew up and when things blow up they are gone, so she subtracted. She also drew a thorough picture, demonstrating conceptual understanding, but when asked to explain her thinking, she simply replied, "a picture."

Skylar had 32 balloons for her birthday. She blew up 30 more balloons. How many balloons does Skylar have now?

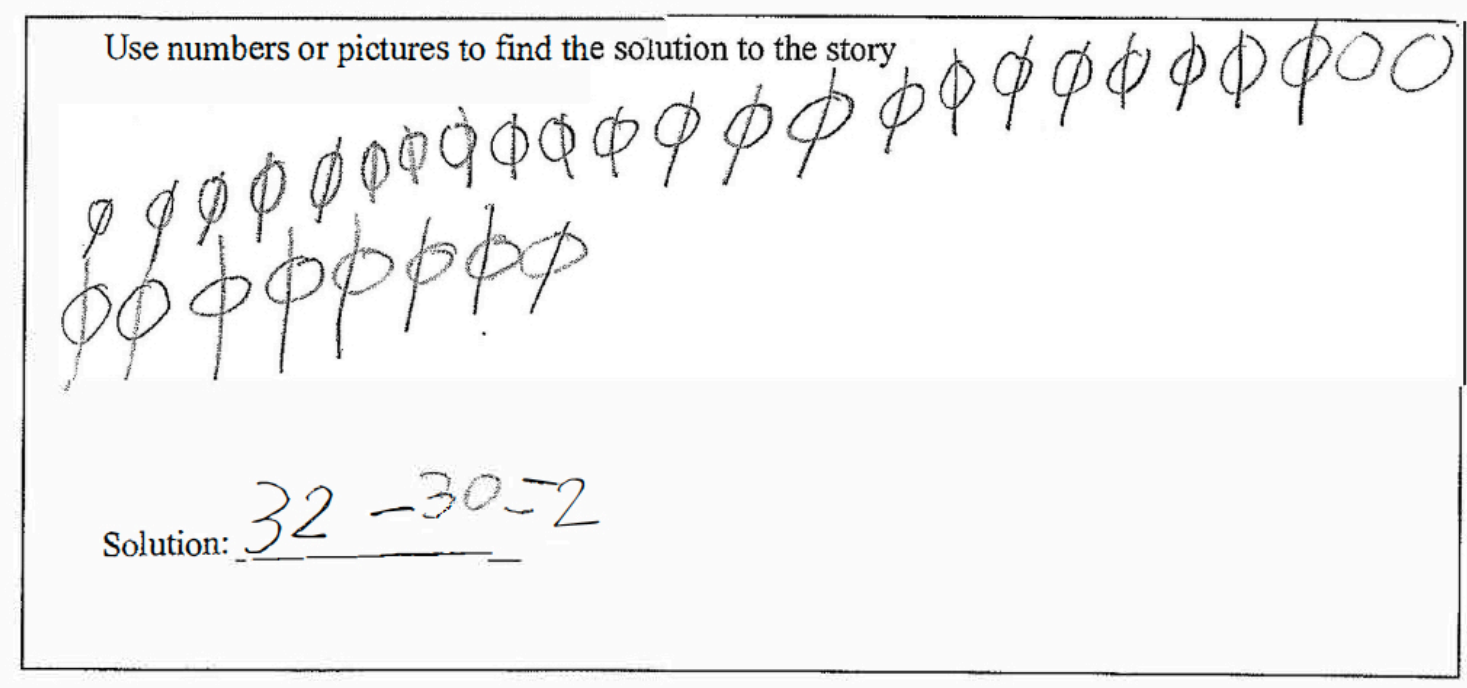

A picture

Figure 3. Paris' Oral Pre-Assessment

Paris' written pre-assessment (Figure 4) had similar results to her oral response, simply stating, "I use blocks." While it is clear from her visual representation that Paris has conceptual understanding of the mathematics, she was unable to explain what she did to solve the problem in writing.

Mrs. Smith had 28 pencils for the class. She found 30 more pencils. How many pencils does Mrs. Smith have now?

Use numbers or pictures to find the solution to the story

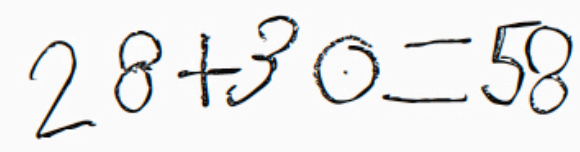

Solution: 58

Use words to explain how you found your solution:

tuse bloksp

Figure 4. Paris' Written Pre-Assessment 


\section{Focus Student 3: Daniel}

Daniel was selected as the third focus student because while his oral response contained more detail than many of his peers, his written response does not explain how he solved the problem. Many students who were able to clearly talk about their solution strategy, were not able to do the same thing in writing. This suggests the importance of developing discourse knowledge within the mathematics classroom to help students understand what is expected in this genre of writing.

On the oral pre-assessment (Figure 5), Daniel clearly describes that 30 plus 30 is 60 and 2 more is 62 . However, his response does not explain where 30 and 30 come from or why he added two more to 60 . This was a common response among the children who were more clearly able to communicate verbally what they did to solve the problem.

\section{Skylar had 32 balloons for her birthday. She blew up 30 more balloons. How many balloons does Skylar have now?}

Use numbers or pictures to find the solution to the story

Solution:

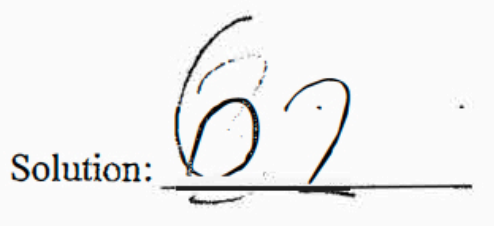

\section{I solved my answer because I counted three plus three and then I added two more and that equals sixty-two.}

Figure 5. Daniel's Oral Pre-Assessment

Daniel's written pre-assessment (Figure 6) was very different from his oral pre-assessment. His response includes the number sentence used to solve the problem but does not explain how the solution was found. Further, Daniel's representation for this problem is very different than the representation he used on the oral preassessment. As described earlier, Daniel did not know how to explain his invented algorithms in writing.

\section{Focus Children Post-Assessment Results}

\section{Focus Child One: Maria}

Like her peers, Maria's oral explanation post-assessment (Figure 7) demonstrates improvement in her ability to explain her mathematical thinking. Although she has the incorrect solution written in her picture, she gives the correct solution at the end in her oral explanation and she is able to explain how she solved the problem, providing a teacher with insights into understandings and/or misunderstandings Maria may have.

Maria's words show that while she is mixing metaphors, that is, 'I was thinking 40 and 2 tens' rather than saying either 40 and 20 or 4 tens and 2 tens, she realizes those two quantities need to be combined. She goes on to say, 'and then I add.' At this point her choice of words is confusing but she says she needs to "take away the 6", suggesting that the six is not connected to her first step of combining the 40 and 2 tens. By taking the 6 away she can combine the 40 and 2 tens and 'you get 60'. She goes on to say that you then need to 'add the 6 back and you get 66'. Though her response is slightly difficult to follow, she clearly has some understanding of the tens and ones and how to combine them. Contrast this to her pre-assessment explanation, "I was thinking in my head and I just knew it. Because $32+30=42$.” which provides no insights into her thinking. 
Mrs. Smith had 28 pencils for the class. She found 30 more pencils. How many pencils does Mrs. Smith have now?
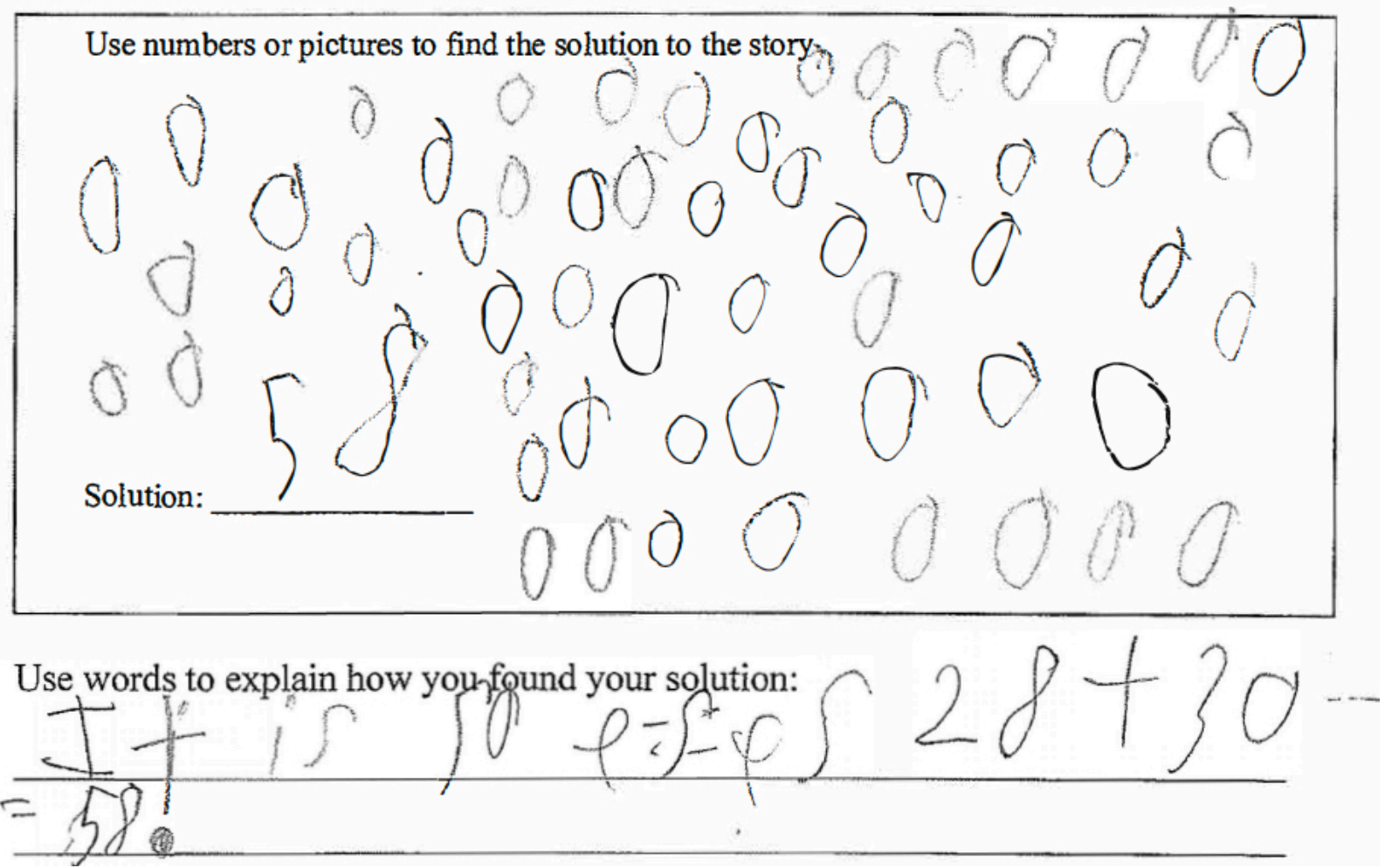

Figure 6. Daniel's Written Pre-Assessment

Joe had 26 rocks in his collection. He went on a walk and found 40 more. How many rocks does Joe have now?

Use numbers or pictures to find the solution to the story

Solution:

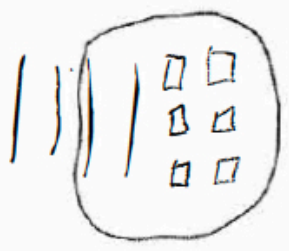

I was thinking that 40 and 2 tens and then 6 ones and I add 2 more take away the 6 and you get 60 and then you add the 6 back and you get 66 .

Figure 7. Maria’s Post Oral Assessment

Her written response (Figure 8) demonstrates the beginning of a conceptual understanding of base ten and how combining tens and combining ones can be used in addition. Also, important to note that invented spelling often used by young children need not necessarily limit their ability to communicate their thinking. 
Eric had 36 cookies for a class party. He baked 40 more cookies. How many cookies does Eric have now?

Use numbers or pictures to find the solution to the story

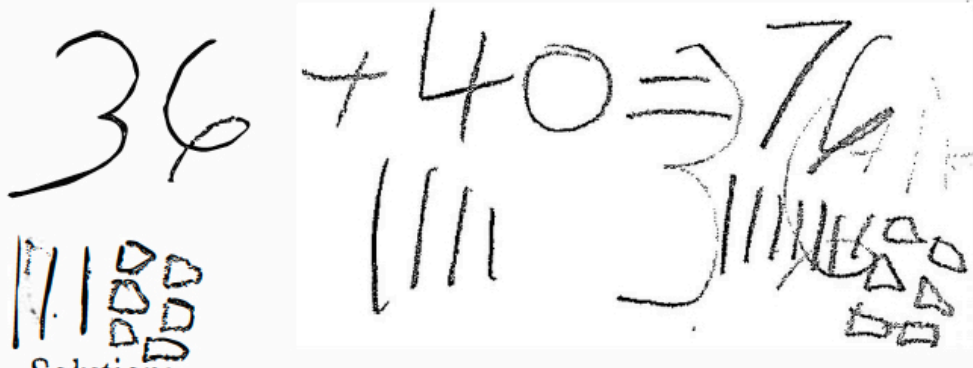

Solution:

Use words to explain how you found your solution:

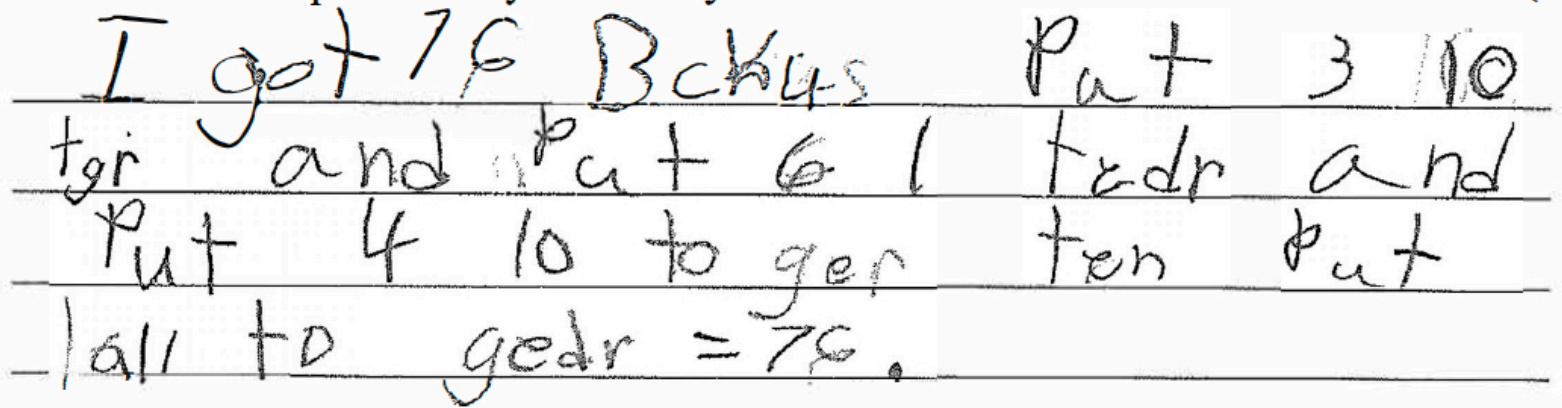

Figure 8. Maria's Post Written Assessment

Joe had 26 rocks in his collection. He went on a walk and found 40 more. How many rocks does Joe have now?

Use numbers or pictures to find the solution to the story

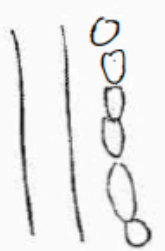

Solution

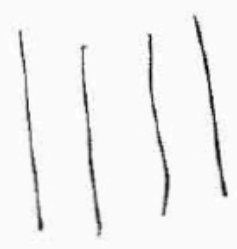

$26+40=66$

I did tens and ones. First I counted the tens and then I count the ones.

Figure 9. Paris' Post Oral Assessment 


\section{Focus Child 2: Paris}

Paris' oral post-assessment (Figure 9) demonstrates a more detailed response, though still somewhat vague. Unlike the pre-assessment she includes the use of mathematical vocabulary such as tens, ones, and count. Through her representation, the reader can determine that she does have conceptual understanding of the mathematics, however, her oral explanation does not indicate how many tens and ones she counted.

Paris' written post-assessment [Figure 10] is much more descriptive than her pre-assessment. She demonstrates through her words an awareness of adding tens to tens and ones to ones, however, she confuses 40 tens for 4 tens. This was a common error noticed throughout the unit.

\section{Eric had 36 cookies for a class party. He baked 40 more cookies. How many cookies does Eric have now?}

Use numbers or pictures to find the solution to the story
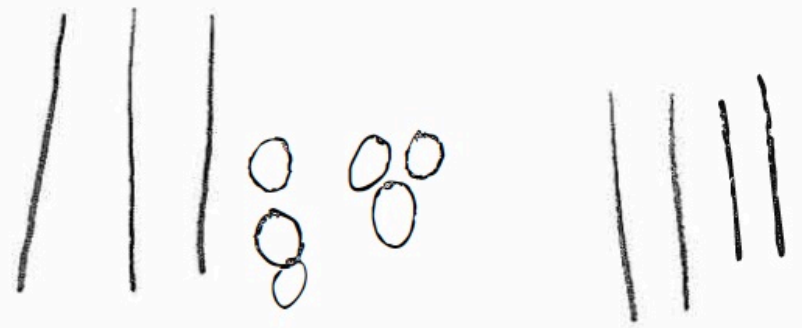

Solution:

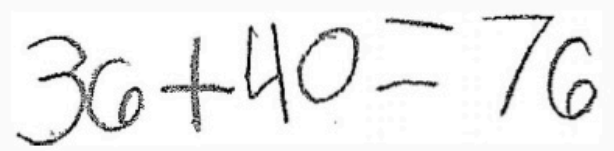

Use words to explain how you found your solution:

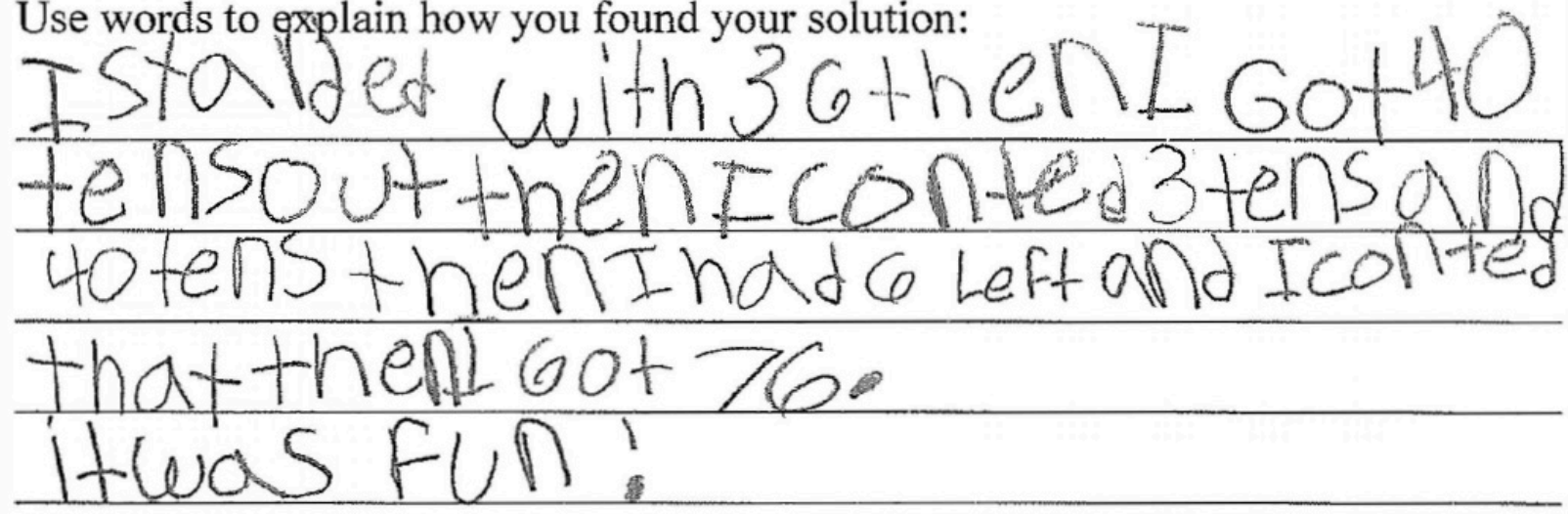

Figure 10. Paris' Post Written Assessment

\section{Focus Child 3: Daniel}

Though Daniel's pre-assessment included more detail than many of his peers, his post-assessment included even more information about how he solved the problem. On the pre-assessment he explains that he added 30 and 30 and then the 2 more. On the post-assessment, he explains that he knows $2+4$ is 6 then $20+40=60$. His next sentence is a bit confusing, he says "then I put $26+40$ equals 66." While he demonstrates an understanding of adding tens to tens, his statement about $26+40$ equals 66 does not explain where he came up with the six ones in 66. Towards the end of the unit, many of the children began using invented algorithms to solve problems and were working towards explaining their strategies. Conversations with Daniel and others using similar strategies revealed that they were adding the tens together, $20+40=60$, so they knew that $26+40=66$. More time to develop sociomathematical norms for explaining invented algorithms would have likely helped him become clearer about his strategy. 


\section{Joe had 26 rocks in his collection. He went on a walk and found 40} more. How many rocks does Joe have now?

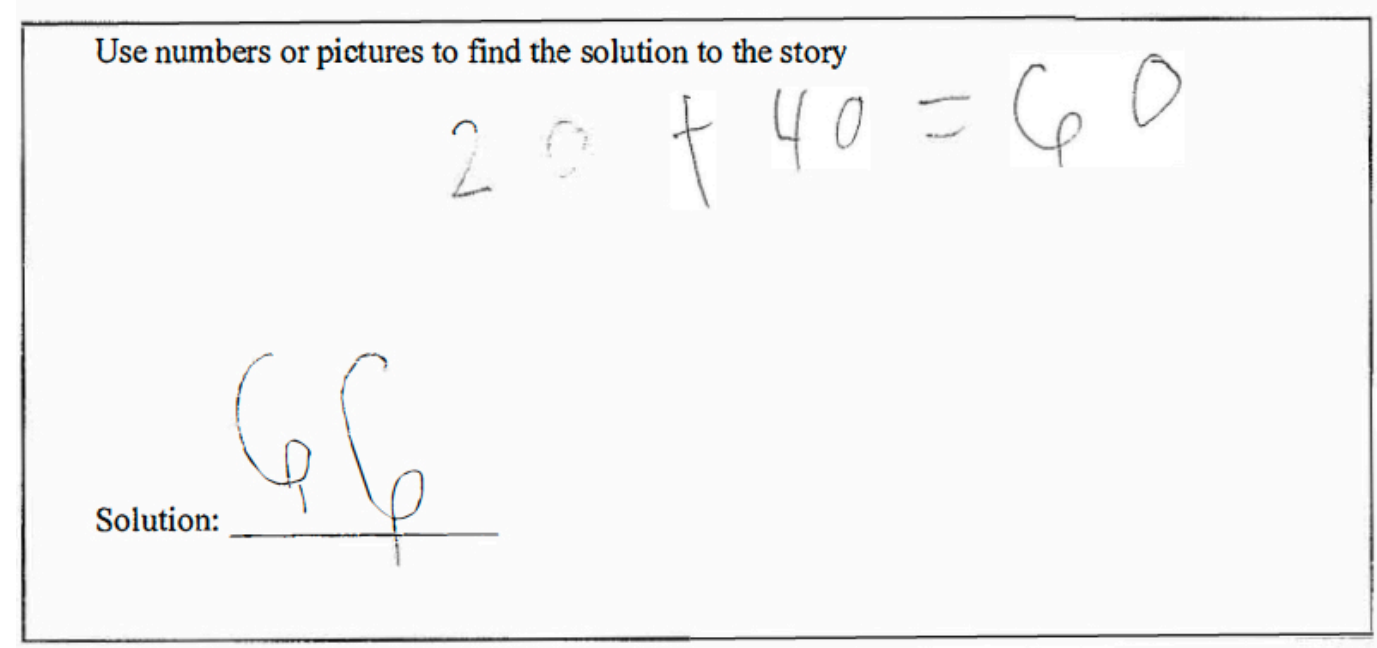

\section{What I did 2 plus 4 and then 40 plus 20 \\ equals 60 then I put 26 plus 40 equals}

66.

Figure 11. Daniel's Post Oral Assessment

Daniel's written post-assessment (Figure 12) also contains more detail than his pre-assessment. His response includes the use of number sentences rather than writing out the words. Because he is in first grade and beginning to explore writing about his thinking, number sentences were expected, therefore, his use of a plus sign and equal sign were considered as using mathematical vocabulary. While his response is more detailed, it contains some errors. He writes that he did $30+4=70$. Here he likely confused 4 tens with 40 while writing, a common error among the students throughout the unit. He then writes $70+6=76$. While his explanation explains exactly what he did to solve the problem, he does not use a linking verb to link the two number sentences for the reader.

Eric had 36 cookies for a class party. He baked 40 more cookies. How many cookies does Eric have now?

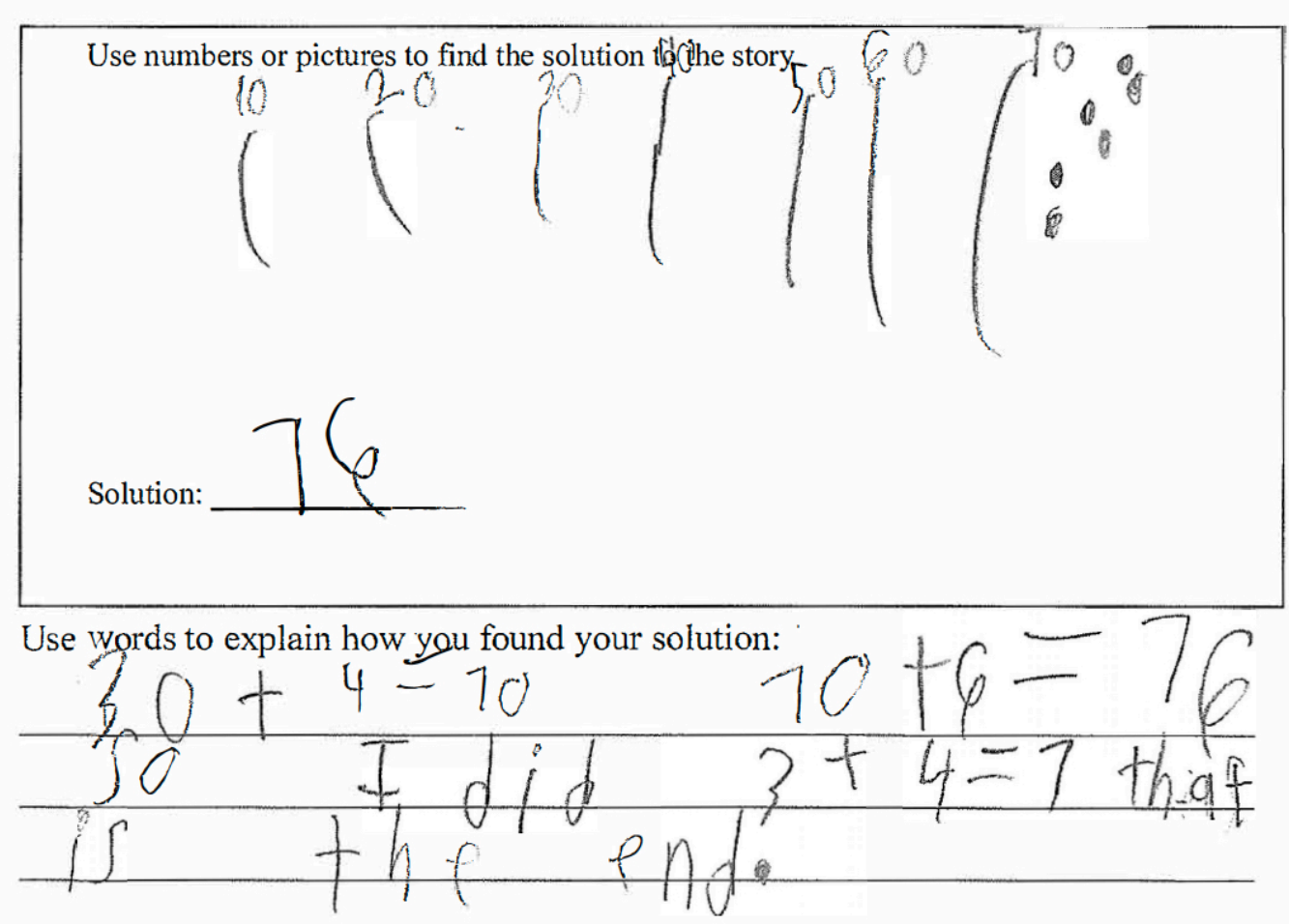

Figure 12. Daniel's Post Written Assessment 


\section{DISCUSSION AND LIMITATIONS}

While children are not expected to write about their mathematical reasoning until the third grade in the U.S. (CCSSELA, 2010), the results of this study suggest a value of adding written discourse to problem-based mathematics instruction in young children's classrooms. The findings can be partially attributed to the development of sociomathematical norms in the classrooms. Focusing on sociomathematical norms, i.e., what is an acceptable, detailed, and understandable explanation of a strategy that was used, enhanced the children in this study's ability to express their thinking orally (Yackel and Cobb, 1996) and in writing. Interestingly, interviews with the teachers prior to the unit revealed that the teachers believed norms for explaining mathematical thinking orally had already been established within each classroom. For example, in the interview with Paris' teacher, she indicated that students were often encouraged to share their solution strategies with the class. When asked how children would talk about their solution strategies, she explained giving a rather sophisticated example, "They might say I knew that $8+8=16$, so I know $8+7=15$. Or if there were a 2 -digit number plus a 2 -digit number they might say well I know 25 has 2 tens and 13 has 1 ten so I knew it was going to have to be 30 something so I added the tens and I added the ones." However, during the unit none of the children in her class responded in this way when explaining how they solved a problem on the pre-assessment, suggesting a disconnect between the children's actual ability to explain their thinking and the teacher's expectations. Additionally, as seen in the student pre-assessment examples, students were at differing levels of development of communicating their thinking, suggesting that what qualified as a clear explanation was not universally developed by the children (Levenson et al., 2009). A few of the children, like Daniel, were explicit in their thinking on the oral pre-assessment explaining that 30 plus 30 equals 60 and plus 2 equals 62, while more typically, others like Paris stated simply they used "a picture." While Paris' response is generic, her written representation demonstrates that she understood the mathematics, she may not have understood exactly what was expected when she was asked, "Can you tell me how you got your answer?" A question such as that often leaves children struggling to comprehend what is expected when they are asked to explain how they found their solution. Therefore, during each lesson of the unit in this study, it was critical that the researcher had explicit conversations with the students about what was an acceptable explanation that could be understood by members of the class, including describing exactly what they did and the steps they took. The need for explicit instruction is consistent with earlier research by Mercer et al. (1999) who found that with 9-10 year olds the use of clear and precise discussions regarding talking with peers about their ideas helped children monitor their thinking and communicate it verbally.

It was also central in the lessons in this study to focus on developing the discourse knowledge specific to the mathematics classroom (McClain and Cobb, 2001). There needed to be intentional attention on the language and vocabulary of mathematics, such as using add instead of put together, to bring further clarity to the written and oral explanations. As demonstrated in Maria's work, at the beginning of the unit most of the children wrote explanations such as, because I knew in my head, I counted, or I drew a picture. By the end of the unit their explanations were more developed, more clearly describing the steps actually taken to find the solution, even when if it were not correct. This development in written explanations can be attributed, at least in part, to the development of discourse knowledge, which is consistent with Fitzgerald and Danielham (1987) who claimed that explicit instruction in the expectations of a genre can enhance children's writing. Williams and Casa (2015) asked children to talk about their thinking and then encouraged them to write down what they talked about, demonstrating a link between talking and writing about mathematical thinking. The importance of connecting oral discourse to written discourse became clear in this study when Daniel explained that he had solved the problem in his head before he got to his seat, but he was not sure how to write what he did. Sharing what he did through talk helped him begin to understand how to write down his thinking in both a representation and sentences. Interestingly, once the children began to understand the expectation for writing about their solution strategy, they started to write what they did before telling their peer as it appeared to solidify their thinking before trying to talk about it, perhaps demonstrating that writing about their strategy was increasing their metacognitive awareness (Pugalee, 2004).

Developing sociomathematical norms and discourse knowledge helped the children in this study more clearly communicate their thinking with their peers. Over the time period of the unit the children began providing added details in their accounts of their solution strategies and they began to learn from each other, over time producing more sophisticated solution strategies such as the use of invented algorithms.

As with Daniel, public conversations between the researcher and individual students also increased the teacher/researcher's awareness of a child's misunderstanding and/or his or her inability to merely communicate ideas. The insights gained by the teacher that are revealed in listening to oral discourse and reading written discourse are invaluable. In this study, oral and written explanations made public the conceptual understanding the students were developing in using base-ten to solve problems, providing valuable knowledge for planning future instruction. Although not documented in this study but noted informally, it appeared that adding written discourse in the two intervention classrooms also impacted not only clarity in communication, but development of conceptual 
understanding as well, an area worthy of further study. If so, this would be consistent with the findings of Cohen et al. (2015), who found that having second-grade children respond to "deep thinking questions" in writing helped develop their conceptual understanding.

Attending to acceptable norms and mathematical language within the lessons gave the students an opportunity to focus their attention on translating their thinking into words (both orally and in writing) without undue concern about the correctness of the mathematics. Once discourse skills developed, the students were then able to attend to the mathematics and their conceptual understanding of adding and subtracting two-digit numbers improved. This is perhaps because students were acquiring the language they needed to share their thinking with a partner. They were then freed up to concentrate on the mathematics and on the ideas of their peers, allowing them to consider other ways to solve the problem.

The process of writing requires the writer to consolidate his or her thinking, helping to clarify knowledge (Neil, 1996). It is important to note then that only focusing on oral discourse and norms for sharing solution strategies did not appear to be enough to significantly improve the comparison groups oral responses. The addition of written explanations appears to have enhanced the intervention group's ability to both talk and write about their solution strategies. In the current study, it appears that writing about how they solved the problem helped the children solidify their strategy for adding two-digit numbers, suggesting the value of the writing process itself.

As with all research, this study has several limitations. This study only looked at the change in student explanations from one school's first-grade classrooms. Therefore, the sample size is small and not randomized. Further, results from different schools could vary based on the instructional practices of the teachers.

Interviews from the four teachers revealed that while they all use the same curriculum, their use of the curriculum varied, leaving the students with differing exposure to the first-grade standards. While every effort was made to teach the same lesson to each of the four classrooms, due to the nature of problem-based instruction, that was not entirely possible.

Also, it is difficult to elicit oral and written discourse without the use of problem-based mathematics instruction that encourages student participation. Future studies need to look at this pedagogical style within other mathematical strands and environments.

As the student, Sharon, in Levenson (2013) asked, "What does it mean to explain?" Many young children are unsure about what is expected when someone asks them to explain how they got their answer. It is important that teachers develop norms for what explaining entails, for sharing solution strategies within their classrooms, and for developing the language of mathematics. Through the use of cognitively demanding tasks which motivate a need to explain and explicit conversations about what it means to explain, the children in this study were more able to clearly share how they solved problems, a valuable first step in developing mathematical competency.

\section{REFERENCES}

Armstrong, R. A. (2014). When to use the Bonferroni correction. The Journal of the College of Optometrists, 34, 502508. https://doi.org/10.1111/opo.12131

Bicer, A., Capraro, R. M. and Capraro, M. M. (2013). Integrating writing into mathematics classroom to increase students' problem solving skills. International Online Journal of Educational Sciences, 5(2), 361-369.

Boaler, J. (2016). Mathematical mindsets: Unleashing students' potential through creative math, inspiring messages and innovative teaching. San Francisco, CA: Jossey-Bass.

Burns, M. (1995). Writing in math class. Sausalito, CA: Math Solutions Publications.

Casa, T. M. (2015). The right time to start writing. Teaching Children Mathematics, 22(5), 269-271. https://doi.org/10.5951/teacchilmath.22.5.0269

Casa, T. M., Firmender, J. M., Cahill, J., Cardetti, F., Choppin, J. M., Cohen, J., ... and Zawodniak, R. (2016). Types of and purposes for elementary mathematical writing: Task force recommendations. Available at: http://mathwriting.education.uconn.edu

Cohen, J. (1988). Statistical power analysis for the behavior sciences (2nd ed.). Hillsdale, NJ: Erlbaum.

Cohen, J. A., Casa, T. M., Miller, H. C. and Firmender, J. M. (2015). Characteristics of Second Graders' Mathematical Writing. School Science and Mathematics, 115(7), 344-355. https://doi.org/10.1111/ssm.12138

Department for Education. (2013). The National Curriculum in England: Key Stages 1 and 2 framework document. Available at: https://www.gov.uk/government/publications/national-curriculum-in-england-primarycurriculum (Accessed 14 June 2018).

Faul, F., Erdfelder, E., Buchner, A. and Lang, A.-G. (2009). Statistical power analyses using G*Power 3.1: Tests for correlation and regression analyses. Behavior Research Methods, 41, 1149-1160. https://doi.org/10.3758/BRM.41.4.1149

Fitzgerald, J. and Danielham, L. (1987). Teaching children about revision in writing. Cognition and Instruction, 4, 324. https://doi.org/10.1207/s1532690xci0401_1 
Fletcher, G. (2016). Pringle ringle. 3-Act Lessons. Available at: https://gfletchy.com/the-pringle-ringle/

Gavin, M. K., Chapin, S. H., Daily. J. and Sheffield, L. J. (2006-2008). Student Mathematician's Journal: Guides for Teaching and Assessing. Project M3 series. Dubuque, IA: Kendall Hunt.

Lee, C. (2006). Language for Learning Mathematics: Assessment for Learning in Practice: Assessment for Learning in Practice. McGraw-Hill Education (UK).

Levenson, E. (2013). Exploring one student's explanations at different ages: The case of Sharon. Educational Studies in Mathematics, 83, 181-203. https://doi.org/10.1007/s10649-012-9447-1

Levenson, E., Tirosh, D. and Tsamir, P. (2009). Students' perceived sociomathematical norms: The missing paradigm. The Journal of Mathematical Behavior, 28, 171-187. https:// doi.org/10.1016/j.jmathb.2009.09.001

Mannion, J. and Mercer, N. (2016). Learning to learn: Improving attainment, closing the gap at Key Stage 3. The Curriculum Journal, 27(2), 246-271. https://doi.org/10.1080/09585176.2015.1137778

McClain, K. and Cobb, P. (2001). An analysis of development of sociomathematical norms in one first-grade classroom. Journal for Research in Mathematics Education, 236-266. https:/ / doi.org/10.2307/749827

Moyer, P. S. (2000). Communicating mathematically: Children's literature as a natural connection. The Reading Teacher, 54(3), 246-255.

National Council of Teachers of Mathematics (NCTM). (2015). Principles to action: Ensuring mathematical success for all. Reston, VA: NCTM.

National Council of Teachers of Mathematics (Ed.). (2000). Principles and standards for school mathematics (Vol. 1). Reston: VA, NCTM.

National Governors Association Center for Best Practices, Council of Chief State School Officers (NGA Center and CCSSO) (CCSSM). (2010). Common core state standards for mathematics. Washington, D. C.: NGA Center and CCSSO.

National Research Council (NRC). (2001). Adding it up: Helping children learn mathematics. J. Kilpatrick, J. Swafford and B. Findell (Eds.). Mathematics Learning Study Committee, Center for Education, Division of Behavioral and Social Sciences and Education. Washington, DC: National Academy Press.

Olinghouse, N. G. and Graham, S. (2009). The relationship between the discourse knowledge and the writing performance of elementary-grade students. Journal of Educational Psychology, 101(1), 37-50. https://doi.org/10.1037/a0013462

Partnership for Assessment of Readiness for College and Careers (PARCC). (2016). PARCC bigh level blueprintsmathematics. Math Test Specification Documents. Available at: http://parcconline.org/assessments/testdesign/mathematics/math-test-specifications-documents

Pont, B. (2018). Curriculum reform: An education change perspective. Dublin, IR: Policy Advice and Implementation Division Directorate for Education and Skills OECD.

Pugalee, D. K. (2004). A comparison of verbal and written descriptions of students' problem solving processes. Educational Studies in Mathematics, 55(1-3), 27-47. https://doi.org/10.1023/B:EDUC.0000017666.11367.c7

Sfard, A. (2012). Introduction: Developing mathematical discourse-some insights from communicational research. International Journal of Educational research, 51, 1-9. https:/ / doi.org/10.1016/j.ijer.2011.12.013

Smith, M. S. and Stein, M. K. (2015). Five practices for orchestrating productive mathematics discussions. Reston, VA: NCTM.

Stein, M. K., Engle, R. A., Smith, M. S. and Hughes, E. K. (2008). Orchestrating productive mathematical discussions: Five practices for helping teachers move beyond show and tell. Mathematical Thinking and Learning, 10(4), 313-340. https:// doi.org/10.1080/10986060802229675

Stigler, J. W. and Hiebert, J. (1999). The teaching gap: Best ideas from the World's teachers for improving education in the classroom. New York: The Free Press.

Wright, D. B. (2003). Making friends with your data: Improving how statistics are conducted and reported. British Journal of Educational Psychology, 73, 123-136. https:/ / doi.org/10.1348/000709903762869950

Yackel, E. and Cobb, P. (1996). Sociomathematical norms, argumentation, and autonomy in mathematics. Journal for Research in Mathematics Education, 458-477. https://doi.org/10.2307/749877

Yackel, E. (1995). Children's talk in inquiry mathematics class rooms. In: Cobb, P.; Bauersfeld, H. (Eds.): The emergence of mathematical meaning: Interaction in classroom cultures. 


\section{APPENDIX A}

Rubric for Mathematical Explanations

\begin{tabular}{|c|c|c|c|c|}
\hline Indicator & 0 & 1 & 2 & 3 \\
\hline $\begin{array}{l}\text { Mathematical Concepts } \\
\text { (Base-Ten) }\end{array}$ & $\begin{array}{l}\text { Student does not provide } \\
\text { a written or oral } \\
\text { explanation. Child did not } \\
\text { have access to the } \\
\text { problem. }\end{array}$ & $\begin{array}{l}\text { Oral or written } \\
\text { explanation demonstrates } \\
\text { that the student has access } \\
\text { to the problem, but has a } \\
\text { lack of procedural and } \\
\text { conceptual understanding } \\
\text { of base-ten concepts. } \\
\text { - does not refer to base-ten } \\
\text { - counts all by ones } \\
\text { - refers to tens and ones but } \\
\text { does not elaborate }\end{array}$ & $\begin{array}{l}\text { Oral or written } \\
\text { explanation demonstrates } \\
\text { partial or inconsistent } \\
\text { understanding of base-ten } \\
\text { addition and subtraction. } \\
\text { - only refers to one quantity } \\
\text { or the result in tens and } \\
\text { ones } \\
\text { - exhibits counting by tens } \\
\text { error, e.g., } 46,56,76 \\
\text { - adding digits }\end{array}$ & $\begin{array}{l}\text { Oral or written explanation } \\
\text { demonstrates a consistent } \\
\text { conceptual understanding } \\
\text { of base-ten concepts } \\
\text { - Counts by tens } \\
\text { - Decomposes numbers into } \\
\text { tens and ones to solve the } \\
\text { problem } \\
\text { - Uses an invented algorithm }\end{array}$ \\
\hline $\begin{array}{l}\text { Mathematical } \\
\text { Communication } \\
\text { Response to: } \\
\text { Can you tell me how you } \\
\text { got your answer? } \\
\quad \text {-OR- } \\
\text { Can you write me a note } \\
\text { about how you got your } \\
\text { answer? }\end{array}$ & $\begin{array}{l}\text { Student does not provide } \\
\text { an oral or written } \\
\text { response or the response } \\
\text { is unintelligible. }\end{array}$ & $\begin{array}{l}\text { Oral or written } \\
\text { explanation only states the } \\
\text { tools used to find a } \\
\text { solution, but does not } \\
\text { refer to how the tools } \\
\text { were used. } \\
\text { - Refers to using tens and } \\
\text { ones without telling how } \\
\text { they were used } \\
\text { - Does not indicate awareness } \\
\text { of operation (added, put } \\
\text { together etc.) } \\
\text { - Refers to use of numbers, } \\
\text { number sentences, pictures, } \\
\text { circles without elaborating }\end{array}$ & $\begin{array}{l}\text { Oral or written } \\
\text { explanation states partially } \\
\text { developed solutions, } \\
\text { reasoning is incomplete. } \\
\text { - Refers to the total quantity } \\
\text { without explaining how it } \\
\text { was obtained } \\
\text { - Refers to the two quantities } \\
\text { in the problem but does not } \\
\text { tell how an answer was } \\
\text { found. } \\
\text { - Refers to one quantity and } \\
\text { the solution } \\
\text { - Refers to counting by tens } \\
\text { strategy but does not } \\
\text { elaborate }\end{array}$ & $\begin{array}{l}\text { Oral or written explanation } \\
\text { states adequately developed } \\
\text { solution. The explanation } \\
\text { clearly describes the steps } \\
\text { taken to find the solution. } \\
\text { - may not be mathematically } \\
\text { accurate, but the explanation } \\
\text { is clear, developed } \\
\text { - explains how quantities were } \\
\text { added (counted, added, put } \\
\text { together, writes a number } \\
\text { sentence) }\end{array}$ \\
\hline $\begin{array}{l}\text { Mathematical } \\
\text { Vocabulary } \\
\text { Terms: (in written, symbol, } \\
\text { or numeral form) tens, } \\
\text { ones, add, subtract, } \\
\text { counted, equals, together, } \\
\text { apart, take away, more, } \\
\text { solved, number sentence, } \\
\text { made }\end{array}$ & $\begin{array}{l}\text { Student does not use a } \\
\text { mathematical vocabulary } \\
\text { term. }\end{array}$ & $\begin{array}{l}\text { Student uses one } \\
\text { mathematical vocabulary } \\
\text { term. }\end{array}$ & $\begin{array}{l}\text { Student uses } 2 \\
\text { mathematical vocabulary } \\
\text { terms. }\end{array}$ & $\begin{array}{l}\text { Student uses three or more } \\
\text { mathematical vocabulary } \\
\text { terms. }\end{array}$ \\
\hline
\end{tabular}

Adapted from Gavin et al., 2006-2008, Rubric for Student Mathematicians Journal 